\title{
La división del trabajo moral: las críticas de J. Habermas a K.-0. Apel en torno a la realización histórica de la ética del discurso
}

\author{
A divisão do trabalho moral: a crítica de J. Habermas a K.-O. Apel em \\ torno da realização histórica da ética do discurso
}

\section{Leandro Paolicchi}

Doctor en Filosofía Universidad Nacional de Mar del Plata, Conicet - Argentina, e-mail: leandropaolicchi@yahoo.com

\section{Resumen}

El trabajo se propone confrontar la solución que Jürgen Habermas ha propuesto para la realización histórica de la ética del discurso con aquella que ha desarrollado el otro creador de esta propuesta, es decir, Karl-Otto Apel. El objetivo que persigue esta confrontación es dejar al descubierto ciertas falencias que pueden observarse en el planteo de Karl-Otto Apel o al menos mostrar la conveniencia de ciertas ideas que a este respecto ha sugerido Jürgen Habermas. En este sentido, la confrontación puede leerse también como la necesidad de complementar lo desarrollado por ambas propuestas como una solución al problema de la realización histórica de la ética del discurso. Sin embargo, el trabajo señala el alto precio que paga el esquema habermasiano - con su reforma de la arquitectónica del discurso - en función de institucionalizar un procedimiento de deliberación discursiva en el marco del Estado democrático de Derecho al punto de abandonar el proyecto de una ética del discurso. Finalmente, en función de los aspectos positivos y de los aspectos negativos de las propuestas de Apel y Habermas, se sugieren unas líneas 
en las que es necesario continuar como una forma de resolver el problema de la realización histórica de la ética del discurso.

Palabras-clave: Ética. Discurso. Aplicación. Normas morales.

\section{Resumo}

O artigo propõe confrontar a solução que Jürgen Habermas propôs para a realização histórica da ética do discurso como essa que desenvolveu o outro criador da proposta, ou seja, Karl-Otto Apel. O objetivo deste confronto é expor algumas deficiências que podem ser vistas sobre a proposta de Karl-Otto Apel, ou pelo menos mostrar a adequação de certas ideias a esse respeito que tem sido sugerido por Jürgen Habermas. Neste sentido, o confronto também pode ser lido como a necessidade de complementar o desenvolvido por ambas propostas como uma solução para o problema da realização histórica da ética do discurso. No entanto, assinala-se o alto preço pago pelo esquema habermasiano - com a sua reforma da arquitetura do discurso - de acordo com a institucionalização de um processo de deliberação discursiva sob o Estado democrático de direito, a ponto de abandonar o projeto de uma ética do discurso. Finalmente, com base nos aspectos positivos e negativos das propostas de Apel e Habermas, sugere algumas linhas que precisam para continuar como uma forma de resolver o problema da realização histórica da ética do discurso.

Palavras-chave: Ética. Discurso. Aplicação. Normas morais.

El problema de una aplicación responsable de principios éticos a la facticidad histórica tiene en Jürgen Habermas características muy diferentes de las que Karl-Otto Apel ha desarrollado en su parte B de la ética del discurso. Sin embargo, el propósito de una exposición amplia de cómo Jürgen Habermas ha entendido tal problema me parece que está con mucho justificada. Primero, porque ha sido Habermas quien junto con Apel ha delineado las estructuras básicas de la ética del discurso y, segundo, porque la forma que tiene Habermas de entender y desarrollar el problema de la aplicación sirve a mi entender para explicitar algunos de los puntos débiles del planteo de Karl-Otto Apel.

Si bien, como se dijo, fueron ambos quienes desarrollaron la ética del discurso, han persistido desde sus tempranos escritos algunas 
diferencias que incluso se extendieron con el tiempo (CORTINA, 1989, p. 538-539; HABERMAS, 1991a, p. 119-226; 2004, p. 36-44). Las dos más importantes diferencias se dieron en los dos planos que Apel ha diferenciado dentro de la ética del discurso. Es decir, dentro del plano de la fundamentación y el de la aplicación. No voy a extenderme demasiado sobre las diferencias en el plano de la fundamentación y sí en cambio lo haré en el plano de la aplicación. Por lo pronto, aquí adelantaré que lo que Apel desarrolla como un problema de aplicación de un principio moral cuando las condiciones para ésta no están dadas adecuadamente no es lo que Habermas entiende como un problema de aplicación propiamente sino como el problema de la justificación de un tipo de prácticas que son necesarias para crear las condiciones que posibilitarán el normal desenvolvimiento de los discursos prácticos (HABERMAS, 2004, p. 41-44; 1998a, p. 125). Es decir, lo que podríamos denominar en términos apelianos un problema de fundamentación de las condiciones de aplicación del principio del discurso. Aquí es donde tiene lugar la conocida postura de Habermas con respecto al módico papel que corresponde a la ética filosófica, limitada a explicitar el moral point of view (HABERMAS, 1991a, p. 94; 1998a, p. 129).

Para Habermas, el discurso mismo no puede ser el encargado de producir las condiciones para un igual acceso de los individuos a los discursos prácticos y este problema de tipo político o, más precisamente, ético-político (HABERMAS, 1998a, p. 125) debe quedar en manos de las ciencias históricas y sociales, la política y el derecho. Aquí Habermas, para sintetizar su posición con respecto a este tema recurre a una frase de Horkheimer que cito: "Para superar el carácter utópico de la idea kantiana de una constitución perfecta, es menester una teoría materialista de la sociedad" (HABERMAS, 1998a, p. 130).

Podría criticársele a esta postura de Habermas cierta unilateralidad innecesaria. No se ve por qué la teoría ética no podría contribuir en algún modo a esclarecer también el problema (llamado por Apel) de la aplicación. Si bien a Apel podría hacérsele notar la falta de una consideración más amplia con respecto a las ciencias de tipo empírico en el problema de la aplicación, no sé por qué debe hacerse recaer todo el problema sobre estas últimas como hace Habermas. 
A mi parecer deberían confluir en este problema de manera necesaria los dos tipos de perspectivas.

Volviendo al punto principal, la respuesta apeliana del problema le resulta a Habermas en extremo insatisfactoria, al punto de que su propia solución ha implicado un replanteo global de su teoría y también una radicalización de sus tesis que lo han apartado de los planteos de Apel, hasta el punto de que éste último lo ha declarado fuera de la propuesta de la ética discursiva ${ }^{1}$.

El argumento principal con el que Habermas critica a Apel es que una teoría deontológica como la ética del discurso, que prescribe un determinado procedimiento para la legitimación de normas universales, no puede dar prioridad normativa a ningún objetivo particular por sobre esas mismas normas debido a que, en palabras de Habermas (2004, p. 43), "la prescripción de tal fin - por más elevado que sea requiere un compromiso entre el razonamiento normativo y el prudencial". Sabemos que Apel (1988, p. 141-153), regula estas relaciones entre una racionalidad ético-discursiva y una racionalidad estratégica mediante lo que ha llamado el "principio de complementación" pero Habermas no ve cómo es posible reconstruir tal principio desde los presupuestos de la argumentación como requiere el procedimiento de reconstrucción pragmática al que adhieren ambos autores. La solución de Habermas apunta a una institucionalización de los procesos de formación democrática de la voluntad dentro del Estado de derecho en donde los ciudadanos puedan participar en el reaseguramiento de las condiciones de acceso a una política de la deliberación.

Este hincapié de Habermas en la institucionalización de canales de acceso para la formación democrática de la voluntad lo ha llevado a tematizar explícitamente y de una manera que incumbe a los fines de este trabajo las relaciones entre la moral, el derecho y la política. Teniendo en cuenta estas relaciones, sus investigaciones han buscado

1 Para una profundización de la crítica de Habermas a la postura apeliana véase además de Facticidad y Validez, Madrid, Trotta, 1998 y también del mismo autor "Zur Architektonik der Diskursdifferenzierung. Kleine Replik auf eine grosse Auseinandersetzung" en Reflexion und Verantwortung. Auseinandersetzungen mit Karl-Otto Apel. In: BÖHLER, D. et al. (Her.). Frankfurt am Main, Suhrkamp, 2003. Las críticas de Apel están en Auseinandersetzungen in Erprobung des Transzendentalpragmatischen Ansatzes. Frankfurt, Suhrkamp, 1998, p. 701-836. 
dilucidar en qué medida una moral que debe aplicarse a la historia de un modo responsable necesita del derecho y en qué medida el derecho, que ya no cuenta con una legitimación religiosa o metafísica, necesita de una legitimación moral.

Pero antes de pasar a esto, mostraré brevemente la arquitectónica habermasiana en la reconstrucción del principio moral y los últimos cambios que ha introducido debido a que son necesarios para comprender algunas modificaciones importantes con respecto al problema de la aplicación del principio del discurso.

\section{La explicitación del principio moral en Jürgen Habermas}

Habermas, al igual que Apel, ha intentado explicitar un principio moral entre los presupuestos de la argumentación en el cual, al igual que en la transformación pragmático-trascendental de la ética kantiana en Apel, ha quedado incluido el principio de universalización propuesto por el filósofo de Königsberg (1998b, p. 88)². Así, Habermas ha identificado en Conciencia Moral y Acción Comunicativa un principio al que denomina postulado de la universalidad (U) que funciona a modo de principio puente excluyendo como inválidas aquellas normas que no tienen la aprobación de todos los posibles destinatarios (HABERMAS, 1998d, p. 83). Sin embargo, Habermas advierte que no se debe confundir este principio con el que representa el postulado básico de la ética del discurso (D) que dice: "Únicamente pueden aspirar a la validez aquellas normas que consiguen (o puedan conseguir) la aprobación de todos los participantes en cuanto participantes de un discurso práctico" (HABERMAS, 1998d, p. 117).

Habermas ha cambiado recientemente esta arquitectónica del discurso. El sentido de estos cambios quedará explicitado más adelante, pero por ahora podemos decir que en Facticidad y Validez, Habermas

2 No voy a introducirme aquí en las diferencias que existen en materia de fundamentación entre Apel y Habermas, es decir, entre una pragmática trascendental que explicita presupuestos irrebasables (nichthintergehbar) de la argumentación, entre ellos el principio de la Ética del Discurso y una pragmática universal que reconstruye de modo hipotético dichos presupuestos. Para una discusión de estas diferencias véase HABERMAS, J. Lawrence Kohlberg und der Neoaristotelismus. In: HABERMAS, J. Erläuterungen zur Diskursethik. Frankfurt am Main: Suhrkamp, 1991b. p. 185-199. 
ha defendido la idea de un principio que expresa el sentido de la imparcialidad de la razón práctica kantiana pero que ahora es neutral tanto con respecto al derecho como a la moral. Habermas (1998c, p. 172) denomina a este principio "principio del discurso" pero es un principio que se refiere a acciones de tipo general: "Válidas son aquellas normas (y sólo aquellas normas) a las que todos los que puedan verse afectados por ellas pudiesen prestar su asentimiento como participantes en discursos racionales".

A partir de este principio neutro, puede especificarse luego un principio moral o lo que Habermas llama un "principio democrático". Ello dependerá del tipo de razones que en cada caso se esgriman para justificar las normas correspondientes. En el caso del principio moral este es pertinente para las normas que sólo pueden justificarse si se tiene en cuenta por igual el interés de todos los afectados (HABERMAS, 1998c, p. 173). En cambio, el principio democrático es un principio operativo para legitimar normas jurídicas y en el que pueden confluir razones de tipo moral, pero también pragmáticas y ético-políticas.

\section{Los límites de la moral postconvencional y la necesidad de una división del trabajo moral}

El problema principal, como se dijo, de una ética-política de la responsabilidad es cómo legitimar (moralmente) acciones que produzcan las condiciones para el normal desenvolvimiento de los discursos prácticos. Es decir, cómo justificar acciones desde un punto de vista moral que serán las que crearán las condiciones óptimas para un normal desarrollo de conductas moralmente acordes o para una salida moralmente legítima de los conflictos de intereses. Entre estas condiciones se encuentra un cierto desarrollo económico, social y cultural que permita una participación calificada de todos los implicados en los discursos prácticos. Pero también la condición de que aquellos que hayan aceptado acatar normas intersubjetivamente reconocidas puedan tener la seguridad de que efectivamente las otras partes guiarán su comportamiento por dichas normas (HABERMAS, 2004, p. 42). Para 
Habermas, este último problema se soluciona con una complementación de la moral por el derecho positivo. De hecho, Habermas cree que en general el problema de una moral que deba hacerse efectiva en la historia sólo puede resolverse con la ayuda del derecho. Así ha dicho: "Pues en las sociedades complejas la moral sólo puede tener efectividad allende el ámbito de lo próximo si queda traducida al código jurídico o código ('justo' jurídico / 'injusto' jurídico) con el que funciona el derecho" (HABERMAS, 1998c, p. 175).

De paso, aquí también puede verse como una complementación de la moral por el derecho debe ser tenida en cuenta si quiere superarse la distinción del sistema de complementariedad entre vida pública / vida privada que preocupaba a Apel. De hecho, Apel ha reconocido la función de complementación que el derecho positivo cumple con respecto a la moral (APEL, 2002, p. 48) ${ }^{3}$ pero también se ha visto obligado a considerarlo en tanto coerción funcional sistémica y por lo tanto restrictiva de lo moral.

Pero, para entender por qué la moral necesita del derecho deberemos reconstruir la génesis de ambos y a su vez describir las características externas que, por así decirlo, los constituyen. Tanto el derecho como la moral y la política se encontraban en las sociedades tradicionales y arcaicas desdiferenciados en una eticidad estructurada en torno a un fundamento sacro o metafísico. Sólo con el surgimiento de sociedades complejas y la pérdida de esa eticidad tradicional dichos ámbitos comienzan a diferenciarse claramente. De todas formas, el mismo origen común puede verse todavía en que tanto la moral como el derecho están abocados a las mismas funciones: coordinar las acciones a través de normas justificadas, ordenar de un modo legítimo las relaciones intersubjetivas y solucionar conflictos de acción (HABERMAS, 1998c, p. 171). Sin embargo, como dice Habermas, y esto es fundamental para entender la interrelación entre ambos ámbitos, la

3 Apel ha dicho: "En tanto el derecho positivo se ha diferenciado de la moral, es precisamente debido a esta diferenciación como se ha constituido - con mucho - en la más importante ayuda externa para la producción de las condiciones de aplicación de la ética discursiva”. APEL, K.-0. La ética discursiva y las coerciones funcionales sistémicas de la política, el derecho y la economía de mercado. Reflexión filosófica acerca del proceso de globalización. In: DAMIANI, A.; MALIANDI, R. ¿Es peligroso argumentar? Estudios sobre política y argumentación. Mar del Plata: Suárez, 2002. p. 49. 
moral postconvencional es sólo una forma de saber cultural entre otras mientras que el derecho cuenta ya con el peso de una obligatoriedad sancionada institucionalmente.

Una moral que se ha desgajado de una eticidad sustancial y que problematiza todos los patrones de acción sancionados por procesos de socialización evaluándolos desde una perspectiva universal puede constituirse en un punto de referencia para la acción, pero ya no es una motivación fuerte para actuar de acuerdo a lo que ella misma ha establecido como justo o correcto (HABERMAS, 1998c, p. 179). De aquí que este tipo de moral necesite para poder jugar su papel en el plano de la acción de agentes dispuestos motivacionalmente a obrar de acuerdo a sus parámetros, es decir, que estén condicionados en instancias de conciencia por procesos de socialización que vayan en ese sentido. Es decir, a nivel general, una moral racional postconvencional solo puede salir de su estado de virtualidad si tiene como puntos de apoyo procesos de socialización y sistemas de la personalidad correspondientes con una moral de ese tipo.

Ahora bien, si una moral de este tipo debiera depender de la actualización de esas condiciones quedaría suspendida en la teoría o en ámbitos subjetivos de conciencia sin poder ser traducida a la práctica o al ámbito objetivo de lo público. Ha sido Habermas quien más ha explorado una vía alternativa para efectivizar una moral postconvencional en la complementación por el sistema jurídico. El derecho como tal está referido directamente a la prescripción de un conjunto de acciones que tienen una eficacia directa en la praxis. A ello se suma que también en el derecho están incluidas motivaciones y valoraciones que aseguran un alto nivel de fuerza motivacional para los preceptos jurídicos. Es este doble componente del sistema del derecho el que lo hace altamente provechoso para colaborar en la tarea de hacer efectiva una moral universalista postconvencional - como la ética discursiva en la facticidad de la historia. Es decir, porque el derecho representa un sistema de saber en el ámbito de la cultura pero también un sistema de acción en el ámbito de la sociedad es que puede cumplir con mayor eficacia dicho papel (HABERMAS, 1998c, p. 180). 
Para Habermas, el derecho libera al actor moral en tres aspectos con el que una moral postconvencional los sobrecarga ${ }^{4}$. La primera de las sobre-exigencias es de tipo cognitivo y está relacionada íntimamente con el carácter formalista de la ética del discurso. En efecto, una moral postconvencional como la ética discursiva sólo puede proporcionar un procedimiento para la legitimación de normas pero no algo así como un conjunto preciso de mandatos para todas las circunstancias. Son los propios individuos los que deben decidir en cada caso mediante un proceso afectado por pugnas y confrontaciones. Sin embargo, la exigencia no está relacionada con esto sino con la decisión sobre conflictos concretos que trascienden ámbitos de interacción familiares. Esto implica una descripción lo más completa posible de la situación que también está sometida a conflictos y luego la elección de una norma aplicable a esa situación. El conjunto de estas cuestiones complejas generalmente sobrepasa la capacidad analítica de un individuo para formar su juicio moral. El derecho descarga en cambio de esta exigencia cuando decide mediante un proceso institucional qué debe ser considerado una norma jurídica y en qué situaciones debe ser aplicada de un modo imparcial.

La otra sobre-exigencia se refiere a la carga motivacional que requiere el seguimiento de una norma moral. Una vez que se ha llegado a una instancia consensual donde una norma ha quedado decidida, los agentes que han tomado parte en el proceso de deliberación deben estar dispuestos a dejarse guiar por lo que se ha decidido (HABERMAS, 1998c, p. 181). El derecho descarga al agente de esta exigencia en la medida en que impone coercitivamente la conducta que la norma prescribe bajo una amenaza de sanción si esta acción no se lleva a cabo. En este sentido, el derecho también aporta una solución a otro problema directamente relacionado con una ética de la responsabilidad como es el problema de la exigibilidad. Este problema ha sido tratado como un problema clásico de la aplicación bajo las categorías de rigorismo y latitudinarismo (MALIANDI, 2004, p. 181-182). Sin embargo, aquí está relacionado con el problema de en qué medida debe exigirse a alguien

4 En realidad, Habermas señala cinco aspectos, pero los tres mencionados son, a mi entender, los más significativos. 
la observancia de una norma válida si no se cumple el supuesto de que a este comportamiento corresponderá un acatamiento también general de dicha norma. En palabras de Habermas (1998c, p. 182): "Todos tienen que poder esperar de todos la observancia de las normas válidas. Las normas válidas sólo son exigibles si pueden de verdad imponerse y hacerse valer contra el comportamiento desviante".

El derecho, al estabilizar las conductas y regularizar las expectativas bajo pena de sanción institucional, garantiza un nivel más amplio de exigibilidad para normas morales acordadas consensualmente. Es entonces esta complementación de la moral por el derecho la que le asegura a la moral una efectividad que por las características propias de una moral postradicional surgida de una "eticidad desgarrada" tendría que verse limitada allí donde los procesos de socialización y de estructuras de la conciencia le fueran favorables. Sin embargo, lo fundamental aquí es que esta moralidad que se traslada al ámbito del derecho no se pierda en el proceso de legitimación de normas jurídicas. Es decir, la relación que debe darse entre los ámbitos autónomos de la moral y el derecho más que de complementación o compensación de este último hacia la primera debe ser de interpenetración. La moral debe migrar y conservarse allí en el proceso legislativo de producción de normas jurídicas. El problema que se abre a partir de esta situación es amplio y altamente complejo. No voy a tratar esta situación por cuestiones de espacio, sino que simplemente mencionaré de qué se trata: entre otras cosas, de asegurar el punto de vista moral dentro de la formación de los acuerdos parlamentarios donde los discursos morales se mezclan con discursos políticos (HABERMAS, 1998b, p. 156). Principalmente se trata de institucionalizar a través de procedimientos jurídicos la imparcialidad - la esencia de la razón práctica - en las decisiones del poder legislativo (HABERMAS, 1998b, p. 157). Aquí no se trata tan solo de hacer efectiva una moral postconvencional, sino, que también es a través de esta institucionalización como puede cobrar validez el derecho positivo y en el fondo toda dominación política ejercida a través de él.

Según Habermas (1998b, p. 170), pensar que los procesos de formación parlamentaria de la voluntad puedan albergar todavía un "núcleo racional en sentido práctico moral no es algo que a primera vista resulte 
tan plausible". Como dije, no voy a discutir este punto álgido de la teoría de Habermas y a la que le dedica la parte más importante de Facticidad y Validez. Puede concedérsele a Habermas que una moral en forma de procedimiento sobreviva en los acuerdos y resoluciones parlamentarias y de esta manera pueda garantizar una moral que se hace efectiva a través de la política y el derecho. Tan sólo me conformo aquí con mostrar a grandes rasgos las relaciones entre la moral y el derecho y su pertinencia para el problema de hacer efectiva una moral en el curso de la historia.

Es de este modo entonces como Habermas entiende cómo puede aplicarse una moral a la facticidad de la historia. Es decir, para Habermas desde el punto de vista de una ética de la responsabilidad no es en absoluto necesaria una parte B de la ética del discurso ni por supuesto menos "un principio de complementación" como piensa Apel. Aquel problema fundamental de una ética política - que deba mediar moralidad y eticidad - de una responsabilidad por el obrar moral cuando no están dadas las condiciones en el sentido del correspondiente acatamiento de las normas por parte de terceros frente a mi propio obrar moral se soluciona sólo cuando las normas cobran obligatoriedad jurídica (HABERMAS, 1998b, p. 166). En este sentido me parece que los planteos de Habermas tienen una ventaja con respecto a los planteos de Apel. Más allá de si es posible o no reconstruir de los presupuestos de la argumentación un principio de complementación, me parece que ese planteo representaba una carga excesiva para el accionar de un individuo. Dicho principio exige de éste que considere situaciones altamente complejas y que evalúe las posibilidades de acción y de combinación de una racionalidad ética con una estratégica. En suma, el planteo apeliano parecía, como se dijo, demasiado irreal y ficticio como para confiarle el objetivo de una ética política de fundamentar las condiciones de aplicación del principio del discurso. En cambio, la ley moral se juega en Habermas en la complementación con el derecho y, por lo tanto, las mediaciones entre una racionalidad comunicativa y la estratégica se dan con el respaldo del derecho positivo. Esto quiere decir, en última instancia, que toda mediación y negociación entre estas dos formas de racionalidad se dan en un marco institucional y sus resultados tienen luego la coacción propia de las normas jurídicas del Estado. 
El problema en esta forma de considerar el tema de la aplicación del principio del discurso es, como se desarrollará más adelante, en qué medida el derecho logra salvar todos los puntos débiles de una moral postconvencional. Lo más significativo aquí no es si el derecho puede lograr o no ese objetivo, sino lo que debe preguntarse es a qué costo lo realiza. A mi entender, toda la compleja trama de relaciones que se ponían en juego en Apel entre una racionalidad estratégica y una racionalidad ético-discursiva a nivel individual Habermas la traslada a un plano institucional. Este me parece uno de los méritos del planteo habermasiano, pero aquí no debe finalizar el juicio. Lo que hay que evaluar es cómo se resuelven también en este plano las relaciones entre estas dos racionalidades.

La solución habermasiana paga un alto costo en términos de la estructura del discurso. Habermas introduce una arquitectónica del discurso reformada y una clasificación de los usos de la razón práctica que lo han apartado mucho de los planteos tradicionales. La razón de esto estriba en que para institucionalizar los procesos de la formación democrática de la voluntad, la moral no es la única perspectiva interviniente sino que, como se dijo, en el principio democrático confluyen además una perspectiva ético-política y una pragmática. Es decir, en el fondo, para que una moral pueda hacerse efectiva a través de un medio jurídico debe hacerse lugar a otros tipos de racionalidades, que sin embargo, se siguen moviendo, a mi entender, en el espectro que va desde una racionalidad moral discursiva hasta una racionalidad de tipo estratégica. Pero para esto Habermas se ha visto obligado a replantear el principio del discurso como neutro moralmente, lo que le ha valido la afirmación de Apel de que éste ha abandonado la ética del discurso y cualquier intento de fundamentación ética.

\section{Algunas consideraciones finales}

Es decir, y para concluir este trabajo, la propuesta de Habermas en torno a la realización histórica de la ética del discurso se presenta como más adecuada pues en ella se tienen en cuenta un conjunto de 
complejos entramados institucionales que dan un marco más realista a la solución por él propuesta. Más allá de las discusiones alrededor de si es posible o no reconstruir desde los presupuestos de la argumentación algo así como un principio de complementación, aun así, con este principio, la solución apeliana parece cargada de una abstracción peligrosa o altamente insuficiente y no tiene en cuenta aspectos que no sólo corresponden a la efectividad de un principio moral sino que son aspectos estructurales del problema de la aplicación o realización histórica de la ética del discurso. El que a mi obrar moral deba corresponder el obrar moral de los otros cuando se ha llegado a un acuerdo sobre determinado tipo de normas no es un problema solo de conformación o no de las condiciones materiales para el actuar moral sino que forma parte de una expectativa recíproca que constituye al obrar moral mismo. En este sentido, el principio de complementación apeliano llega demasiado tarde para dar una solución que de todas maneras es insuficiente.

Con respecto a la solución apeliana, la propuesta habermasiana de una complementación por parte del derecho, y la inevitable mediación de la política, asegura de una manera más satisfactoria esta expectativa recíproca que no sólo se presenta en ámbitos donde las condiciones materiales para el actuar moral no están suficientemente dadas sino que se muestra constitutiva de todo obrar moral. El problema relevante que aparece en Habermas para quien desea permanecer dentro de los planteos de una ética del discurso es que su reforma arquitectónica de los discursos prácticos lo aleja claramente, como dice Apel, de la fundamentación de una ética a partir de los presupuestos de la argumentación. Es una tarea altamente significativa el poder conjugar lo mejor de ambos planteos. Es decir, conservar el detallado complejo institucional que se delinea en Facticidad y Validez en función de hacer efectivos ciertos principios normativos - que todavía es posible extraer desde dentro del discurso - con la idea esencialmente apeliana de una fundamentación fuerte de principios normativos de la razón práctica. Es una tarea que por razones de espacio no puedo desarrollar aquí pero que he intentado esquematizar en otra parte (PAOLICCHI, 2009) y a la que remito para quien desee continuar la discusión. 


\section{Referencias}

APEL, K.-O. Kann der postkantische Standpunk der Moralitat noch einmal in substantielle Sittlichkeit aufgehoben werden?. In: APEL, K.-O. Diskurs und Verantwortung. Frankfurt: Suhrkamp, 1988. p. 103-153.

APEL, K.-O. Auseinandersetzungen in Erprobung des Transzendentalpragmatischen Ansatzes. Frankfurt Am Main: Suhrkamp, 1998.

APEL, K.-O. La ética discursiva y las coerciones funcionales sistémicas de la política, el derecho y la economía de mercado. Reflexión filosófica acerca del proceso de globalización. In: DAMIANI, A.; MALIANDI, R. ¿Es peligroso argumentar? Estudios sobre política y argumentación. Mar del Plata: Suárez, 2002. p. 23-54.

CORTINA, A. La ética discursiva. In: CAMPS, V. (Ed.). Historia de la ética, Tomo III: la ética contemporánea. Barcelona: Crítica, 1989. p. 533-576.

HABERMAS, J. Erläuterungen zur diskursethik. Frankfurt am Main: Suhrkamp, 1991a.

HABERMAS, J. Lawrence Kohlberg und der Neoaristotelismus. In: HABERMAS, J. Erläuterungen zur diskursethik. Frankfurt am Main: Suhrkamp, 1991b. p. 185-199.

HABERMAS, J. ¿Afectan las objeciones de Hegel a Kant también a la Ética del Discurso? In: HABERMAS, J. Escritos sobre moralidad y eticidad. Barcelona: Paidós, 1998a. p. 97-130.

HABERMAS, J. ¿Cómo es posible la legitimidad por vía de legalidad?. In: HABERMAS, J. Escritos sobre moralidad y eticidad. Barcelona: Paidós, 1998b. p. 131-177.

HABERMAS, J. Facticidad y validez. Madrid: Trotta, 1998c.

HABERMAS, J. Conciencia moral y acción comunicativa. Barcelona: Península, 1998d. 
HABERMAS, J. Zur Architektonik der Diskursdifferenzierung. Kleine Replik auf eine grosse Auseinandersetzung. In: BÖHLER, D. et al. (Her.). Reflexion und Verantwortung: Auseinandersetzungen mit Karl-Otto Apel. Frankfurt am Main: Suhrkamp, 2003. p. 44-64.

HABERMAS, J. La ética del discurso y la cuestión de la verdad. Buenos Aires: Paidós, 2004.

MALIANDI, R. Ética: conceptos y problemas. Buenos Aires: Biblos, 2004.

PAOLICCHI, L. Discurso y facticidad. Mar del Plata: Suárez, 2009.

Recebido: 20/08/2011

Received: 08/20/2011

Aprovado: 30/11/2011 Approved: 11/30/2011 